\title{
Integración y agrupación en las cooperativas vascas
}

\author{
Iñigo Nagore \\ Abogado economista
}

Recibido: 22-11-2016

Aceptado: 20-12-2016

Sumario: 1. Introducción: intercooperación y colaboración económica. 2. Cooperativas de segundo y ulterior grado. 2.1. Objeto. 2.2. Socios: capacidad, ingreso y baja. 2.3 Régimen económico. 2.4. Estructura orgánica y derecho de voto. 2.5. Liquidación. 2.6. Transformación. 2.7. Normativa supletoria. 3. Agrupaciones empresariales. 4. Acuerdos intercooperativos. 5. Corporaciones cooperativas. 5.1. Objeto. 5.2. Consejo de Control y Dirección. 5.3. Régimen supletorio. 6. Grupos cooperativos. 6.1. Antecedentes. 6.2. Concepto. 6.3. Ámbitos grupales. 6.4. Incorporaciones. 6.5. Formalización e modificación de compromisos. 6.6. Clases. 6.7. Efectividad del régimen de grupos cooperativos. 6.8. Control registral. 6.9. Responsabilidad entre miembros del Grupo y entre estos y la cabecera. 7. Cooperativas mixtas. 7.1. Definición y objeto. 7.2. Derecho de voto en la Asamblea general. 7.3. Régimen legal aplicable a las partes sociales con voto.7.4. Participación en excedentes. 7.5. Modificaciones de derechos $u$ obligaciones de alguno de los dos colectivos. 7.6. Regla especial de liquidación.

Resumen: Enraizando la integración y la agrupación cooperativa en el principio de intercooperación, se analiza la legislación vasca en la materia, desde los acuerdos entre cooperativas a los Grupos cooperativos, pasando por las Cooperativas de segundo y ulterior grado y las Corporaciones cooperativas, con referencias comparadas a la legislación estatal. Por último, se abordan las Cooperativas mixtas por estar englobadas dentro del mismo Capítulo de la Ley vasca.

Palabras clave: Integración cooperativa. Principio de intercoooperación. Agrupación cooperativa. Acuerdos entre cooperativas. Cooperativas de segundo y ulterior grado. Corporaciones cooperativas. Grupos cooperativos. Cooperativas mixtas. Ley de Cooperativas de Euskadi. Ley de Cooperativas.

Abstract: Cooperative integration and association should be grounded in the principle of intercooperation to analyse the Basque legislation on the matter, ranging from agreements between cooperatives to cooperative groups, through to second and higher-level cooperatives and cooperative corporations, with comparative references to state legislation. Finally, this 
paper addresses joint cooperatives, as they are included in the same Chapter of the Basque law.

Keywords: Cooperative integration. Principle of intercooperation. Cooperative group. Agreement between cooperatives. Second and higher-degree cooperatives. Cooperative corporations. Cooperative groups. Joint cooperatives. Basque Cooperative Law. Cooperative Law. 


\section{Introducción: intercooperación y colaboración económica}

Los orígenes del Principio de Intercooperación pueden remontarse a Rochdale, dado que «el documento elaborado por los pioneros de Rochdale en 1814 ya hacía mención de la necesidad de la integración cooperativa, al establecer: "Que tan pronto sea posible, esta sociedad procederá a organizar las fuerzas de la producción, la distribución, la educación y el gobierno, o sea establecer una colonia autosuficiente en donde exista unidad de intereses a bien de ayudar a otras sociedades para el establecimiento de colonias similares" $» 1$.

Recogido por la Alianza Cooperativa Internacional, es actualizado en su Congreso de Manchester de 1995:

" "Cooperación entre Cooperativas. Las Cooperativas sirven a sus socios lo más eficazmente posible y fortalecen el movimiento cooperativo trabajando conjuntamente mediante estructuras locales, nacionales e internacionales".

En el Informe anexo a la Declaración, la propia ACl explica la importancia de este Principio, afirmando que "nunca ha sido más importante como Principio que en los años 1990".

La intercooperación debe practicarse tanto a nivel institucional como empresarial. Las Cooperativas sólo pueden maximizar impacto mediante la colaboración rigurosa de unos con otros. Se han de buscar los beneficios de la organización a gran escala a la vez que se mantienen las ventajas de implicación y asentamiento locales (difícil equilibrio de intereses: reto perpetuo para las estructuras Cooperativas y una prueba para el ingenio cooperativo).

La Declaración concluye: "Las Cooperativas deben reconocer, incluso más que el pasado, la necesidad de reforzar sus organizaciones y actividades de apoyo y deben ser capaces de ver que existe un interés cooperativo general, basado en el valor de la solidaridad y el principio de la cooperación entre Cooperativas. Son absolutamente necesarias las organizaciones de apoyo cooperativo general" $»^{2}$.

\section{En cuanto a sus facetas y siguiendo a PAZ CANALEJO y VICENT CHULIA:}

1 ABERTO FARIAS, C. La integración cooperativa como necesidad impostergable, en Anuario de Estudios Cooperativos 1990, Universidad de Deusto, Bilbao, 1991, pág. 135.

2 SALABERRIA AMESTI, J. El Movimiento Asociativo Cooperativo Vasco, en Anuario de Estudios Cooperativos 1997, Universidad de Deusto, Bilbao, 1998, pág. 49 y publicada también en Actualidad en torno al Cooperativismo Vasco, XVI Cursos de Verano y IX, Cursos Europeos de la Universidad del País Vasco, Consejo Superior de Cooperativas de Euskadi, Vitoria, 1998, pág. 58. 
"La noción de "integración cooperativa" puede considerarse idéntica a la de "intercooperación" (THORDARSON) y sirve para designar el fenómeno del asociacionismo con fines económicos entre Cooperativas, con multitud de formas (contratos, cooperativas e incluso sociedades civiles y mercantiles, con tal de que éstas estén controladas por Cooperativas) y de ámbitos: intrasectorial (en el que siempre ha sido más fácil), intersectorial (en el que los fines predominantes son ya de representación unitaria del cooperativismo, en orden a crear una estrategia de poder social frente a los Estados y organizaciones supraempresariales)» ${ }^{3}$. Y es que, "la integración cooperativa pretende ser la respuesta a un doble reto: a) el reto de la "crisis del medio", es decir, la continua amenaza de que las empresas cooperativas en el estadio de la colaboración y concentración empresarial, sean absorbidas por el sector capitalista ("aspecto externo"); b) la cooperación intercooperativa como prolongación de la autoayuda, que ya se realiza a nivel de cada Cooperativa, pero se revela insuficiente, desde un punto de vista técnico y económico, por lo que debe imitar los procedimientos de obtención de mayores dimensiones empresariales y especialización en producciones y mercados, del mismo modo que hacen las empresas capitalistas, pero sin abandonar los principios y métodos cooperativos» ${ }^{4-5}$.

En igual sentido, BUITRON indica que «dos son las tendencias de la cooperativa que constituyen la esencia de su proyección desde y hacia la sociedad; por una parte está su necesidad de agruparse por intereses económico-empresariales y, por otra, la de asociarse como factor inherente al espíritu del movimiento cooperativo, generando y consolidando relaciones de intercooperación y representación a través de una estructura que puede ser local, regional, nacional o internacional, que implica el ejercicio pleno de su autonomía y de su capacidad de organización» ${ }^{6-7}$.

3 VICENT CHULIA, F. y PAZ CANALEJO, N., Ley General de Cooperativas, 3 volúmenes en Comentarios al Código de Comercio y legislación mercantil especial, directores SANCHEZ CALERO, F. y ALBADALEJO, M., Tomo XX, Edersa, 1989, pág. 873.

4 Ibid, págs. 873 y 874.

5 Sobre la integración cooperativa, puede verse, entre otros, MARTINEZ CHARTERINA, A., Análisis de la integración económica, Universidad de Deusto, Bilbao, 1990, en especial págs. 11 a 19 y EMBID IRUJO, J. M., Modelos de integración en VIII Jornadas Cooperativas de Euskadi: La integración societaria: Europa, 1993, Vitoria, 1989, págs. 39 a 62.

6 GADEA, E. / BUITRON, P. / NAGORE, I., Derecho de las Cooperativas (Análisis de la Ley 4/1993, de 24 de junio, de Cooperativas del País Vasco), Universidad de Deusto, Bilbao, 1999, pág. 334.

7 Sobre la evolución legislativa de los grupos y asociaciones cooperativas, pueden verse: GADEA, E., Análisis de las directrices generales de la legislación sobre Coopera- 
En estas materias la Ley de Cooperativas de Euskadi (LCE) presenta, según su Exposición de Motivos, "uno de los aspectos más característicos e innovadores» en el «tratamiento que hace de la integración y agrupación económico-empresarial cooperativa».

Si bien el principio de intercooperación bastaría para justificar las diversas formas de colaboración intercooperativa, a modo de resumen ${ }^{8}$, pueden señalarse razones económicas, financieras y directivas como justificadoras de la existencia de grupos empresariales, agrupaciones empresariales, acuerdos intercooperativos u otras formas de colaboración económica.

Sus formas son diversas, pero, resumidamente, puede decirse que «en una primera manifestación, la concentración de sociedades se presenta bajo simple forma contractual. Es un acuerdo o convenio el que actúa de aglutinante entre las distintas sociedades. El convenio lo mismo sirve de instrumento para agrupar sociedades en sentido horizontal (...), que para realizar concentraciones verticales (...). Otras veces, el vínculo de unión entre sociedades no tiene esa naturaleza y es de orden puramente financiero (...). Pero todavía no se agotan ahí las facetas del fenómeno. Aún existe el modo de unión personal de las sociedades por virtud de la elección o nombramiento de administradores comunes $^{9}$.

Dentro de la vertiente económica de la intercooperación, existen diversas fases y es que «la intercooperación es un estadio inicial o una primera etapa de un proceso normal de acercamiento entre diferentes entidades que, con un gradual y progresivo aumento de relaciones, puede concluir con colaboraciones múltiples, con creación de plataformas comunes (...) y hasta con procesos de fusión» ${ }^{10}$.

tivas en España, Boletín de la Asociación Internacional de Derecho Cooperativo, número 32/1999-I, págs. 71 y ss. y NAGORE, I., Análisis de la evolución legislativa española en materia cooperativa entre 1942 y 1993, Boletín de la Asociación Internacional de Derecho Cooperativo, número 32/1999-I, págs. 129 y ss.

8 FERNANDEZ, Z., Introducción a los grupos, en Grupos Empresariales de la Economía social en España, Directores: J. BAREA, J.F. JULIA y J.L. MONZON, CIRIEC-España. Valencia, 1999, pág. 35, cuadro C.1.2.

9 VICENT CHULIA, F. y PAZ CANALEJO, N., op. cit., pág. 636.

10 SANZ SANTAOLALLA, J., Asociaciones cooperativas, en Glosa a la Ley de Cooperativas de Euskadi, Director PAZ CANALEJO, N., Consejo Superior de Cooperativas de Euskadi, Vitoria, 1999, pág. 513. En igual sentido, DUQUE, JUSTINO F. y RUIZ, J. I., Los grupos en el ordenamiento jurídico, en Grupos Empresariales de la Economía social en España, Directores: BAREA J., JULIA J.F. y MONZON J.L., CIRIEC-España, Valencia, 1999, pág. 109. 
Como recuerda EMBID IRUJO ${ }^{11}$, «la integración cooperativa vendría a ser la fórmula empleada para trasladar a dicho sector empresarial la compleja temática del grupo de sociedades».

Las cooperativas no se han mantenido al margen del mercado y de los «procesos de transformación estructural de la economía y han edificado, a su vez, grandes grupos empresariales en determinados sectores. En España es conocido el grupo Mondragón Corporación Cooperativa - M.C.C.— $)^{12}$.

Así, se deduce que las cooperativas han avanzado en la construcción de grupos ${ }^{13}$ exprimiendo el texto de la anterior Ley, cuando no al margen de la misma. Era preciso una adecuación del marco legal que permitiera "que las cooperativas —aun sin perder sus peculiaridades y principios - salgan del "ghetto» al que las ha recluido una doctrina cooperativa excesivamente purista y alejada de la realidad. Para ello no basta con que la cooperativa pueda participar en sociedades de capital — con fines de gestión y no de mera inversión capitalista- sino que también debe admitir inversiones, nacionales o extranjeras, procedentes de inversores y, sobre todo, de sociedades de capital, en especial para potenciar estrategias de colaboración con ellas en el campo de la innovación tecnológica, de la especialización industrial y de la distribución y apertura de nuevos mercados» ${ }^{14}$.

11 EMBID IRUJO, J. M., Problemas actuales de la integración cooperativa, RDM, núm. 227, Madrid, 1998, pág. 11.

12 CHAVES, R., Grupos Empresariales del a Economía Social: un análisis desde la experiencia española, en Grupos Empresariales de la Economía social en España, Directores: BAREA, J., JULIA, J. F. y MONZON, J. L., CIRIEC-España, Valencia, 1999, págs. 67 y 68.

13 Sobre grupos cooperativos, puede verse: Grupos Empresariales de la Economía Social en España, AAWV, Directores: Barea J., Juliá J. F. y Monzón J. L., CIRIEC España, Valencia, 1999 (tras una parte general, se analizan: Mondragón Corporación Cooperativa, Grup Empresarial Cooperativ Valenciá, Grupo Caja Rural y Grupo Anecoop, S. Coop.).

Sobre MCC puede, adicionalmente, verse: ERDOCIA, J., Dimensiones de las cooperativas MCC y su adaptación a los mercados, en Boletín Asociación Internacional de Derecho Cooperativo, Núm. 30/1998-I, Universidad de Deusto, Bilbao, 1998, págs. 25 y SS.; CELALLA ULIBARRI, A., Estructura y problemática de la Corporación MCC, en Anuario de Estudios Cooperativos, Universidad de Deusto, Bilbao, 1992, págs. 109 a 129 y NAGORE, I., Normas de Intercooperación en Mondragón Corporación Cooperativa, en Boletín Asociación Internacional de Derecho Cooperativo, Núm. 33-1999-II, Universidad de Deusto, 1999, págs. 87 y ss.; Encuadre histórico del nacimiento del Movimiento Cooperativo de Mondragón, Boletín de la Asociación Internacional de Derecho Cooperativo, Universidad de Deusto, número 31/1998-II, Bilbao, 1998, págs. 175 y ss. y Análisis de la evolución del marco estatutario de Caja Laboral Popular (1959-1993), Boletín de la Asociación Internacional de Derecho Cooperativo, Universidad de Deusto, número 29/1997-II, Bilbao, 1997, págs. 337 y ss.

14 VICENT CHULIA y PAZ CANALEJO, op. cit., pág. 885. 
Y en tal sentido, con mayor o menor éxito, ha caminado la vigente Ley $27 / 99$ y gran parte de la legislación cooperativa autonómica ${ }^{15}$, siendo la legislación vasca pionera por estar en ella radicada uno de los buques insignia de los Grupos Cooperativos.

Será la Asamblea General, de cada cooperativa, la competente para la constitución de cooperativas de segundo grado y de grupos cooperativos o incorporación a estos si ya están constituidos y la participación en otras formas de colaboración económica (artículo 31.3.g de la LCE).

Previéndose en la LCE, "con criterio muy amplio, otras modalidades de colaboración económica de carácter más instrumental. A la hora de regular estas otras formas de colaboración con participación de sociedades cooperativas, se reconoce la plena capacidad de éstas cual fuera su clase, nivel o grado, tanto para constituir instrumentos y vínculos contractuales o personificados, como para incorporarse a los ya constituidos. Pretende con ello la nueva Ley no sólo disipar cualquier duda al respecto de los operadores jurídicos y económicos, sino también salir al paso de una actividad olvidadiza, y hasta reticente, a la hora de exponer a diversos sectores empresariales las características del método cooperativo, no pocas veces presentado como una alternativa menor o casi inaplicable por presuntas trabas legales» (E. de M.).

Y sigue diciendo que «según esta Ley, las cooperativas pueden plantearse cualesquiera escenarios de colaboración, entre sí o con otras personas o entidades, con tal de que quede a salvo la finalidad básica de la institución; ello equivale a decir que en muy contados supuestos existirá impedimento jurídico para los proyectos de acción económica a los que pueda incorporarse una cooperativa» (E. de M.).

\section{Cooperativas de Segundo y ulterior grado}

\subsection{Objeto (artículo 128 LCE y 42.2 RRCE)}

La LCE establece que las cooperativas de segundo o ulterior grado tienen por objeto completar, promover, coordinar, reforzar o integrar

15 Decía EMBID IRUJO, con exactitud y realismo, que «sería deseable, de lege ferenda, la promulgación de una ley armonizadora del vasto material normativo existente en España sobre cooperativas. Pero, si tal solución se revela, como parece, imposible, habría que propugnarla, cuanto menos, para los asuntos propios de la integración cooperativa que, por su misma esencia, tienden a trascender las limitadas fronteras de las Comunidades Autónomas (EMBID IRUJO, J. M., Problemas actuales..., op. cit., pág. 35). 
las actividades económicas de sus entidades miembros y del grupo resultante (art. 128.1, primer párrafo).

A diferencia de la LC, que establece que las cooperativas pueden revestir la forma de cooperativa de primero y segundo grado (art. 1.4 LC), desapareciendo el tradicional ulterior grado, la LCE mantiene la tradicional clasificación.

A través de dicho objeto, «la cooperativa de segundo grado no podrá llegar a absorber y anular todas las áreas y manifestaciones de actividad propias de cada una de las empresas socias» ${ }^{16}$.

Dada la amplitud del objeto de estas cooperativas, y para fijar diversos aspectos básicos del mismo, la LCE exige que en los Estatutos Sociales se concreten los siguientes aspectos:

- Sentido y extensión o alcance de la misma.

- Enumeración de las facultades esenciales que quedan transferidas a los órganos de dicha cooperativa.

- Las materias o áreas respecto de las cuales las propuestas de las entidades asociadas serán meramente indicativas, y no vinculantes, para la cooperativa de segundo grado.

- Y, en el caso de que la cooperativa se constituya con fines de integración empresarial, las áreas de actividad empresarial integradas, las bases para el ejercicio de la dirección unitaria del grupo y las características de éste.

Igualmente, la LCE establece dos cautelas o aclaraciones, una respecto a las transferidas y otra relativa a la interpretación de las dudas sobre la propia transferencia.

Así, respecto de las transferidas, se establece que dichas facultades tienen la misma permanencia que el propio objeto social, no pudiéndose revisar su ejercicio ante los órganos de las sociedades integradas. Todo ello, sin perjuicio de la tutela judicial a la que expresamente se remite.

La segunda sirve para aclarar las dudas sobre la transferencia o no de la facultad, al establecerse la presunción de que están transferidas todas las facultades directamente relacionadas con el objeto social de la cooperativa de segundo o ulterior grado, teniendo además prioridad los acuerdos e instrucciones de ésta frente a las decisiones de cada una de las entidades agrupadas (art. 128 LCE).

16 PAZ CANALEJO, N., Ante la nueva Ley Estatal de Cooperativas: Algunos puntos críticos, en Anuario de Estudios Cooperativos 1998, Universidad de Deusto, Bilbao, 1999, pág. 471. 
Como señala EMBID IRUJO, con la cooperativa de segundo grado «son compatibles, a nuestro juicio, muy diversos grados de integración. Y aunque su razón de ser básica es precisamente la de servir de marco organizativo a dicho proceso económico, también resulta adecuada para fines de mera colaboración empresarial» ${ }^{17}$.

Y es que, como se reconoce en su Exposición de Motivos: "la Ley aborda la regulación de las cooperativas de segundo o ulterior grado con el propósito de ofrecer un cauce normativo realista a los fenómenos de agrupación intercooperativa, tan huérfanos hoy día de disciplina jurídica adecuada como necesitados de un marco que, sin perjuicio de salvaguardar la identidad de las instituciones implicadas en aquellos procesos, tenga en cuenta la necesidad de atender a las exigencias de una efectiva colaboración empresarial. A tal fin, ésta podrá ser tan intensa como admitan las sociedades al autorregular sus grupos, aunque sin llegar a anular o prescindir de cada cooperativa agrupada».

El RRCE (artículo 42.2) establece que las cooperativas de segundo o ulterior grado deben precisar en los Estatutos Sociales las facultades transferidas desde la cooperativa de primer grado a la de segundo o ulterior, así como los demás extremos señalados en el artículo 128 LCE que acabamos de ver.

\subsection{Socios: capacidad, ingreso y baja (artículo 129 LCE)}

\section{A. Marco general. Capacidad}

La LCE establece que pueden ser miembros de pleno derecho de estas sociedades las cooperativas de inferior grado y los socios de trabajo. No obstante, se admite, además, a cualquier entidad y persona jurídica, sea de naturaleza pública o privada, pero sin que puedan ostentar en su conjunto más de la mitad del total de los votos existentes en la cooperativa de segundo o ulterior grado ${ }^{18}$. Este límite es un límite máximo, previendo expresamente la LCE la posibilidad de reducirlo en los Estatutos Sociales ${ }^{19}$.

Igualmente, pueden existir socios colaboradores con arreglo a lo regulado en el artículo 19.2 de la Ley.

17 EMBID IRUJO, J. M., Problemas actuales ... op. cit., pág. 23.

18 Con esta apertura a socios no cooperativas, se supera el diseño endogámico que era característico de estas cooperativas, aunque con los límites que se indican (E. de M.).

19 Se flexibilizan los límites de la LC, artículo 77.1. El cómputo de votos frente a socios y el porcentaje (cincuenta frente a cuarenta y cinco por ciento) es diferente que en la LC. 
Como requisito, se exige en los socios una convergencia de sus intereses o necesidades y una ausencia de prohibición en el Estatuto.

\section{B. INGRESO}

Con carácter general, la admisión de cualquier socio persona jurídica requiere acuerdo favorable del Consejo Rector de la cooperativa de segundo o ulterior grado, adoptado por mayoría cualificada de al menos dos tercios de los votos presentes y representados.

No obstante, la LCE contempla expresamente que cabe establecer en Estatutos:

- Otra mayoría para el acuerdo de admisión.

- Requerir periodos de vinculación provisional o a prueba de hasta dos años.

- Atribuir la decisión sobre la admisión a la Asamblea General20.

Respecto de las personas físicas (socios de trabajo y socios colaboradores personas físicas), entendemos que debe estarse a la regulación general de las mismas contenida en la propia LCE.

\section{BAJA}

La baja de los socios personas físicas no está expresamente regulada, por lo que debemos acudir a la regulación general de la Ley, tanto para los socios de trabajo como para los socios colaboradores que lo sean.

Respecto de la baja de los socios personas jurídicas, se establece que deben cursar un preaviso de al menos un año, del cual podrá exonerarle el Consejo Rector ${ }^{21}$.

Además, el citado Consejo Rector puede obligarlo a cumplir las obligaciones contraídas con la cooperativa de segundo o ulterior grado, o a resarcirla económicamente, y ello aún antes de su efectiva separación.

Igualmente, se establece que, salvo previsión estatutaria contraria, la entidad separada debe continuar desarrollando, durante un plazo no

20 Esta posibilidad fue introducida en la primera reforma de la LCE, Ley $1 / 2000$, de 29 de junio, BOPV núm. 146, 1 de agosto, artículo 16.

21 La posible exoneración fue introducida en la primera reforma de la LCE, artículo 16. Se aclaraban así las dudas interpretativas que suscitaba la literalidad imperativa del artículo 129.3 (preaviso sin excepción), en relación al artículo general de calificación de bajas (26.4), que permitía al Consejo Rector calificar la baja de voluntaria aun mediando incumplimiento. Con la reforma, se resolvió definitivamente la duda a favor de la regla general. 
inferior a dos años 22 , los compromisos adquiridos con anterioridad a la fecha de la baja.

\subsection{Régimen económico (artículo 130 LCE)}

\section{A. ApORTACIÓn OBLIGATORIA}

Las aportaciones obligatorias al capital social, de una cooperativa de segundo o ulterior grado vasca, se deben realizar en función de la actividad cooperativa comprometida con aquella por cada socio ${ }^{23}$.

Esta regulación fue ampliada en la primera reforma de la LCE del año $2000^{24}$, remitiéndose en cuanto al compromiso a lo que establecieran los Estatutos, los cuales pueden establecerlo conforme a las reglas generales del artículo 58.1 de la LCE 25 o en razón al número de socios $^{26}$. Se establece con este último criterio una opción específica para las cooperativas de segundo o ulterior grado, dado que el otro es una remisión a la norma general.

Los Estatutos deben fijar los criterios o módulos que definen la actividad cooperativa.

22 Parece así que cabe aumentarlo estatutariamente.

23 Sobre el voto proporcional a la participación en la actividad cooperativizada, RUIZ PERIS recordará «que el número de votos que corresponderá a cada socio estará en constante variación y que tendrán que ser tomados datos de carácter económico para poder determinar el número de votos que corresponde a cada socio en cada Asamblea, lo que exige una documentación empresarial al día» (DUQUE, J. y RUIZ PERIS, J. I., Los grupos en el ordenamiento jurídico, en Grupos Empresariales de la Economía Social en España, Directores: BAREA, J., JULIÁ, J.F y MONZON, J.L., CIRIEC-España, Valencia 1999, pág. 191).

Igualmente, afirma que «es razonable pensar que quienes más usen de la cooperativa serán quienes más poder económico tendrán, con lo que se otorga poder político en la sociedad cooperativa a aquellos que poseen mayor poder económico» (Ibid, pág. 170).

24 Artículo 17 de la Ley 1/2000.

25 Esto es, según los distintos tipos de socios previstos en la LCE o en función de su naturaleza física o jurídica, o para cada socio en proporción al compromiso o uso potencial que cada uno de ellos asuma de la actividad cooperativa.

26 Sobre esta otra variable de voto proporcional, el mismo RUIZ PERIS dirá que «especial complejidad presentará el control de la realidad del número de socios activos que declara tener cada cooperativa, ya que aunque el número total de socios es fácil de controlar el hecho de que se trate o no de socios "activos" parece cuestión más compleja (...). El sistema de control parece bastante complejo y destinado a encarecer y enlentecer las reuniones o a ser decididamente ignorado prescindiendo de cualquier tipo de control, en tanto las declaraciones de las sociedades no se presenten a los ojos de los otros socios como escandalosamente falsas» DUQUE, J. y RUIZ PERIS, J.I., op. cit., pág. 172). 


\section{B. DistRIBUCIÓN DE RESULTADOS}

La distribución de resultados, tanto positivos como negativos (pérdidas), debe acordarse en función de la actividad cooperativa comprometida estatutariamente previa imputación a los fondos de reserva y, en su caso, al Fondo de Educación y Promoción.

\subsection{Estructura orgánica y derecho de voto (artículo 131 LCE)}

\section{A. La Asamblea General}

La Asamblea General está formada por un número de representantes de los socios personas jurídicas, proporcional al derecho de voto de cada entidad socia y, en su caso, por los representantes de los socios de trabajo.

Aunque la LCE no los cite, parece evidente que, de existir socios colaboradores o contemplarse su posible existencia, deberá igualmente regularse la representación de los mismos, dado el derecho general de participación en la misma.

Cabe también destacar que se diseña la Asamblea General como un órgano de representación indirecta por el que los asistentes representan a otros. Esto es criticable dado que, si bien no cabía otro sistema para representar a las personas jurídicas socios, no ocurría lo mismo con los socios de trabajo, que parecen obligados a designar representantes según se establezca en Estatutos.

Respecto al número de representantes de los socios personas jurídicas, se establece la posibilidad de fijar en los Estatutos Sociales límites máximos y mínimos ${ }^{27}$.

Por otro lado, se regula que el derecho de voto de las entidades es proporcional a su participación en la actividad cooperativa o al número de socios.

Por último, se limita el número de votos de una entidad no cooperativa, de forma que no puedan ser superiores a un tercio de los votos sociales, con la excepción de que existan menos de cuatro socios ${ }^{28}$.

27 Esta posibilidad de limitar su número se introdujo en la primera reforma de la LCE, artículo 18.

28 Como indicaba RUIZ PERIS al referirse al límite de la LC: «Este límite no es verdaderamente eficaz para evitar casos de control al estar fijado sobre el número de votos totales existentes. El absentismo de las cooperativas y el hecho de que el límite esté referido a la participación individual de cada socio, y no se trate de un límite acumulativo a la participación conjunta de todas las entidades pertenecientes a un grupo, permiten 
Estas reglas deben ser calificadas como de insuficientes, por cuanto que «en la actualidad (...) es posible controlar una cooperativa mediante mecanismos de control interno dependientes del número de votos poseídos en la Asamblea General, y por supuesto a través de las técnicas de administradores cruzados tan típicas en las entidades cooperativas que permiten a un colectivo, a veces de opinión, controlar las sociedades cooperativas pertenecientes al grupo» 29 .

\section{B. El Consejo Rector}

La administración de las cooperativas de segundo o ulterior grado corresponde a un Consejo Rector. Éste estará compuesto, salvo previsión estatutaria en contra ${ }^{30}$, por un número máximo de quince miembros, debiendo estar representadas en el mismo todas las entidades socias. Esta representación puede ser directa o indirecta.

La LCE prevé el caso de que el número de entidades socias supere el máximo legal o estatutario de miembros, posibilitando que las que tengan menor número de miembros puedan agruparse a efectos de designar sus representantes, remitiéndose por lo demás a las previsiones estatutarias o reglamentarias internas que regulen la materia.

Dentro del Consejo Rector, el derecho de voto puede ser proporcional a la actividad cooperativa o al número de socios de la entidad o entidades a las que representan los consejeros, con el mismo límite ya señalado para la Asamblea General.

Igualmente, cabe establecer en estatutos que hasta un tercio de los miembros del Consejo Rector puedan ser designados mediante cooptación. Esto es, por los miembros del Consejo ya elegidos. Se prevé, en

prever fácilmente situaciones de control de hecho y de derecho en este tipo de cooperativas» (DUQUE, J. y RUIZ PERIS, J.I., op. cit., pág. 170).

29 Ibid., pág. 137.

30 La posibilidad de establecer un máximo superior en Estatutos, fue introducida en la primera reforma de la LCE, artículo 18 de la Ley 1/2000. Dicha modificación se hizo sin duda a petición de alguna cooperativa afectada que encontraba dificultades para mantener las proporciones legales y dar cabida a todos los representantes que quería. Por otro lado, no parece que exista ningún motivo para limitar a 15 el número de miembros más allá de evitar que se acabe convirtiendo en un órgano poco operativo, lo cual puede suceder cuando está compuesto por demasiados miembros. No obstante, el mismo motivo serviría para fijarlo en 14 o en 16. Es igualmente curioso que de entenderse la medida como necesaria no se introdujera una cautela similar en las cooperativas de primer grado. 
tal caso, que la elección deberá realizarse entre personas capacitadas, sean o no miembros de alguna cooperativa del grupo ${ }^{31}$.

\subsection{Liquidación (artículo 132 LCE)}

Producida la disolución de la cooperativa de segundo o ulterior grado, y en caso de realizarse la liquidación, la LCE prevé que el activo sobrante se distribuya entre los socios en proporción al importe del retorno recibido en los últimos cinco años. Cuando la duración de éstas ha sido inferior a este plazo, se toma el de la constitución.

Para el supuesto de que no haya existido ningún retorno en los últimos cinco años, se establece que se distribuya en proporción a la participación de cada socio en la actividad cooperativa o, en su caso, al número de miembros de cada entidad agrupada en aquella cooperativa.

\subsection{Transformación}

A diferencia de la LCE (artículo 77.5), que prevé la transformación de estas cooperativas de segundo y ulterior grado en cooperativa de primero, en la LCE no se regula la cuestión, a nuestro juicio, acertadamente, dado que consideramos que esa operación no constituye transformación alguna.

Y ello pese a lo señalado en la Exposición de Motivos de la LC, «la posibilidad de transformación de una cooperativa de segundo grado en una de primero, que absorbe, tanto a las cooperativas que la integraban, como a sus socios, permite una auténtica integración cooperativa».

Las razones son las indicadas por PAZ CANALEJO, que se referirá críticamente a la misma:

«... existe una novedad importante, que está mejor inspirada y rebozada que diseñada normativamente; se trata de una operación mutadora de la Cooperativa de segundo grado que se califica como transformación y absorción (...). Analizada con algún detenimiento esa operación parece que debe ser objeto de las siguientes matizaciones:

31 A diferencia de lo dispuesto en la LC, no hay referencias a interventores, Comité de Recursos, ni liquidadores. En general, el régimen de la LCE es más flexible y tiene menos límites que el de la LC (verse el artículo 77.1 de LC). 
(...) No hay, hablando con rigor, una transformación (pues no existe cambio de forma jurídico-cooperativa y emigración hacia un molde societario civil o mercantil). Hay una reconversión por desnivelación o "degradación", es decir, literalmente una pérdida de grado o nivel de la Cooperativa secundaria que, por funcionar ésta a modo de filial común de las Cooperativas miembros, también podría calificarse como "desfiliación". Y, a la vez, se produce una "compresión o refundición de Sociedades", puesto que donde antes había al menos 3 entidades (la de segundo grado y dos de primer grado) pasa a subsistir una sola Cooperativa de primer grado.»32.

\subsection{Normativa supletoria (artículo 133 LCE)}

La LCE, «en evitación de problemas que en otros ámbitos territoriales ya se han producido no (...) ordena una rígida e inmediata aplicación supletoria de la normativa sobre las cooperativas de primer grado» (E. de M.), sino que establece una curiosa jerarquía normativa:

1. Normativa específica de la LCE. Esto es, artículos 128 a 132 de la LCE.

2. Estatutos de la cooperativa de segundo o ulterior grado.

3. Reglamento de Régimen Interno de la cooperativa de segundo o ulterior grado.

4. En defecto de lo anterior, y cuando lo permita la específica función y naturaleza de las cooperativas de segundo o ulterior grado, lo establecido en la LCE sobre cooperativas de primero.

El artículo parece querer subrayar la autonomía reguladora de las cooperativas de segundo o ulterior grado frene a las de primero. Así, se aplicaría la normativa específica, luego los estatutos en desarrollo y consonancia con la anterior, y después el Reglamento de Régimen Interno ${ }^{33}$. Después de ellos vendría la regulación que se entendiera apli-

32 PAZ CANALEJO, N., Ante la nueva..., op. cit., pág. 87.

33 La figura del Reglamento de Régimen Interno es muy conocida en el mundo cooperativo pese a no estar regulada. En principio, se trata de un desarrollo estatutario que no necesita de elevación a público, ni goza del control de legalidad del Registro de Cooperativas. Puede ser tal un acuerdo o un conjunto de ellos, pudiéndosele dar tal nombre específicamente o no. Salvo desarrollo estatutario de que se entenderá como tal y elevación de quórum para su adopción, podría serlo cualquier acuerdo de Asamblea General o al menos cualquier acuerdo podría venir a modificarlo de forma expresa (si lo deroga o modifica) o tácita (si lo regula de otra manera) y al ser posterior se interpreta que lo ha modificado. 
cable a las cooperativas de segundo o ulterior grado de la establecida en la LCE a las de primero.

Creemos que la redacción es mejorable, pudiendo citar como ejemplo la similar del artículo 77.6 de la Ley de Cooperativas (Ley 27/1999), que establece que, salvo en los aspectos regulados específicamente para tales, las cooperativas de segundo grado se rigen por la regulación de carácter general establecida en la Ley de Cooperativas, en todo lo que resulte de aplicación.

No cabe dar mayor rango normativo a un Estatuto o a un Reglamento de Régimen Interno que a una Ley (en lo que le resulte aplicable). Lo que si cabe es indicar que éstas se podrán regular de otra forma donde la Ley no sea de carácter imperativo, sino caiga dentro de la autonomía de voluntad de las partes (dispositiva).

La Ley siempre será preferente al Estatuto y al Reglamento, pero en lo que sea aplicable y en lo que resulte imperativa, interpretación armónica con lo declarado en la Exposición de Motivos.

\section{Agrupaciones empresariales (artículo 134 LCE)}

La LCE reconoce a las cooperativas vascas que, con independencia de la posibilidad de constituir cooperativas de segundo y ulterior grado, y cualquiera que sea su clase y nivel, pueden constituir sociedades, asociaciones, agrupaciones, consorcios y uniones de empresas de cualquier clase, entre sí o con otras personas físicas o jurídicas, privadas o públicas ${ }^{34}$.

Así, «regula las "joint ventures", sean intercooperativas, o con otras empresas» ${ }^{35}$, o en palabras de DUQUE, se reconoce "la libertad contractual, tan necesaria para lograr una adaptación a las circunstancias cambiantes de la economía, siempre con el respeto a principios que se encuentran por encima de los intereses y voluntades de los particulares. Especialmente cuando se trata de una formación societaria, como la cooperativa, dirigida a obtener fines económico-sociales mediante la prestación de servicios a sus asociados» ${ }^{36}$.

34 El artículo 79 de la LC no menciona las asociaciones, incluyendo en cambio, de forma expresa, la formalización de convenios o acuerdos. Adicionalmente, declara aplicables los beneficios otorgados por la legislación sobre agrupación y concentración de empresas a las cooperativas que concentren sus empresas por fusión o constitución de otras cooperativas de segundo grado.

35 VICENT CHULIA, F., op. cit., pág. 534.

36 DUQUE, J. y RUIZ PERIS, J. I., op. cit, pág. 114. 
Además, las cooperativas pueden poseer participaciones en cualquiera de las entidades mencionadas para el mejor cumplimiento, desarrollo o garantía de su objeto social.

En cuanto a las cooperativas de crédito y de seguros, la LCE establece que deben respetar ante todo su normativa específica para realizar las operaciones previstas en el artículo 134 ya comentado anteriormente.

\section{Acuerdos intercooperativos (artículo 134 bis LCE) ${ }^{37}$}

La primera reforma de la LCE introdujo un nuevo artículo 134 bis.

En dicho artículo se establece que las cooperativas pueden suscribir con otras acuerdos intercooperativos en orden al cumplimiento de sus objetos sociales. Dado el principio de libertad contractual imperante en nuestro ordenamiento jurídico, poco se aportaba hasta este punto a lo ya existente, sirviendo sólo para recordarlo y acabar con algunas dudas.

La novedad es la declaración de que, en virtud de dichos acuerdos, la cooperativa y sus socios pueden realizar operaciones de suministro, entregas de productos o servicios en otras cooperativas firmantes del acuerdo, teniendo tales hechos la misma consideración que las operaciones cooperativizadas con los propios socios.

Dada la no distinción en la LCE entre resultados cooperativos y extracooperativos, sólo puede entenderse la necesidad de este artículo, no tanto por razones mercantiles, como por razones fiscales ${ }^{38}$.

\section{Corporaciones cooperativas (artículo 135 LCE y 11.4 y DA2. ${ }^{\text {RRCE) }}$}

\subsection{Objeto}

Las corporaciones cooperativas son agrupaciones empresariales constituidas mayoritariamente por cooperativas de primero y segundo o ulterior grado, cuyo objeto es la definición de políticas empresariales, su control y, en su caso, la planificación estratégica de la actividad de sus socios, así como la gestión de los recursos y actividades comunes.

37 Ley 1/2000, artículo 20.

38 El artículo 134 bis de la LCE es literalmente idéntico al 79.3 de la LCE, salvo la eliminación en la vasca de su segundo párrafo, que venía a obligar a imputar el resultado de estas operaciones al fondo de reserva obligatorio. 


\subsection{Consejo de Control y Dirección}

Las facultades de administración de la Corporación deben distribuirse estatutariamente entre un Consejo de Control y un órgano de dirección que puede ser unipersonal o colegiado. No cabe pertenecer simultáneamente a ambos órganos. Se establece así un sistema dualista de administración (E. de M.).

Dichas facultades deben constar en los Estatutos de las corporaciones cooperativas (DA 2. ${ }^{a}$ RRCE) ${ }^{39}$.

El Consejo de Control es el encargado de fiscalizar la gestión de la Dirección y es competente en admisión y baja de socios, régimen disciplinario y designación y revocación de los miembros de la Dirección, debiendo además autorizar los actos de administración extraordinaria que se hayan determinado como tales (los criterios básicos) en Estatutos.

La Dirección asume las funciones gestoras y directivas de la corporación cooperativa y la representación ante terceros.

\subsection{Régimen supletorio}

En todo lo no regulado expresamente en el artículo 135 de la LCE, a las Corporaciones cooperativas se aplica lo dispuesto para las cooperativas de segundo o ulterior grado.

\section{Grupos cooperativos (artículo 135 bis LCE, 24 RLCE y 11.4 y DA 7. $\left.{ }^{\mathrm{a}} \mathrm{RRCE}\right)$}

La primera reforma de la LCE introdujo en la legislación cooperativa vasca la figura de los Grupos cooperativos ${ }^{40}$, ampliándose reglamentariamente su regulación posteriormente. La regulación es casi literalmente coincidente con la del artículo 78 LC, por lo que la doctrina sobre ésta resulta aplicable.

39 El RRCE también prevé, como para las restantes cooperativas, la inscripción del nombramiento y cese de administradores, miembros de la Comisión Ejecutiva, Consejeros Delegados, Directores Gerentes y miembros de la Comisión de Vigilancia (artículo 11.4).

40 Ley 1/2000, artículo 20. 


\subsection{Antecedentes}

La primera regulación de los grupos cooperativos ${ }^{41}$ se produce, como en tantas ocasiones, desde el ámbito fiscal ${ }^{42}$, al desarrollarse la previsión contenida en la Ley 20/1990, de 19 de diciembre, reguladora del régimen fiscal de las cooperativas, apartado tres de la disposición final segunda, que establecía que el Gobierno, a propuesta del Ministerio de Economía y Hacienda, dictaría las normas necesarias para la adaptación de las disposiciones que regulan la tributación sobre el beneficio consolidado de los grupos de sociedades, a las especialidades de las sociedades cooperativas que, en virtud de las reglas estatutarias, mantengan relaciones de vinculación en el ejercicio de sus actividades empresariales.

En base a tal delegación, se dicta el Real Decreto, de 6 de noviembre, número 1345/1992 ${ }^{43}$, que viene a definir, a los efectos del régimen de declaración consolidada, el grupo de sociedades cooperativas como el conjunto formado por una entidad cabeza de grupo y las cooperativas que tengan la condición de socio o asociada de aquella sobre las que ejerza poderes de decisión, en virtud de sus reglas estatutarias.

La entidad cabeza del grupo de sociedades cooperativas, puede ser una sociedad cooperativa o cualquier otra entidad, siempre que, en este último caso, su objeto exclusivo sea el de planificar y coordinar el desarrollo empresarial y las estrategias a largo plazo de las cooperativas que integran el grupo, no pudiendo estar participada por otras personas o entidades diferentes a estas últimas (art. 1.2 RD 1345/1992).

Las relaciones de vinculación, deben implicar el compromiso de redistribuir solidariamente el excedente neto obtenido por cada una de las cooperativas integrantes del grupo de sociedades cooperativas; con un mínimo del 25 por 100 del excedente neto una vez deducidos

41 Sobre la definición de los grupos en el derecho español, pueden verse: DUQUE J. y RUIZ PERIS, J. I., op. cit., págs. 104 a 106; VICENT CHULIA, F., op. cit., págs. 548 y 549 y FERNANDEZ RUIZ, J. L. y MARTIN REYES, M. A., Fundamentos de Derecho Mercantil, Tomo I, segunda edición, Edersa, Madrid, 1999, pág. 529. Y sobre Grupos y Asociaciones Cooperativas en general: NAGORE, I., Grupos y Asociaciones Cooperativas en la Ley General de Cooperativas de España, Boletín de la Asociación Internacional de Derecho Cooperativo núm. 34, Universidad de Deusto, págs. 115 a 146.

42 Igual sucedió en cuanto a los grupos societarios no cooperativos. Así lo señala ROJO, A., Los Grupos de Sociedades en el Derecho español, RDM, Núm. 220, Madrid, 1996, págs. 458 a 460.

43 BOE de 5 de diciembre de 1992, número 292. 
los impuestos y las cantidades destinadas con carácter obligatorio, por imperativo de la Ley (entonces LGC núm. 3/1987), a los fondos de reserva y debe realizarse en forma directamente proporcional al importe económico de las operaciones, actividades y servicios cooperativizados realizados por los socios de las cooperativas miembros del grupo. Igualmente, se exigía la constancia en escritura pública suscrita por todas ellas, así como en sus respectivos estatutos (art. 1 puntos 3 y 4 RD 1345/1992).

Por último, se establecía que cuantas facultades, responsabilidades y obligaciones estén establecidas en el ordenamiento jurídico tributario respecto de la sociedad dominante de un grupo de sociedades, se atribuyen a la entidad cabeza de grupo, en tanto ello no se opusiera a lo establecido en el propio Real Decreto (art. 7 RD 1345/1992).

\subsection{Concepto}

La regulación del grupo cooperativo en una Ley general sustantiva de cooperativas fue novedosa. Según la Exposición de Motivos de la LC: "las especiales características de las sociedades cooperativas han hecho necesaria la regulación del grupo cooperativo, con la finalidad de impulsar la integración empresarial de este tipo de sociedades, ante el reto de tener que operar en mercados cada vez más globalizados» ${ }^{44}$.

Exposición prácticamente coincidente con la de LCE (reforma de la Ley 1/2000), que señala que se "crea una nueva figura jurídica inexistente hasta ahora, cual es la de los grupos cooperativos, asentada en el principio de intercooperación con la finalidad de impulsar nuevas modalidades de integración empresarial de sociedades cooperativas ante los retos cada vez más exigentes de tener que operar en mercados profesionalmente más globalizados: mercados que demandan nuevas soluciones jurídicas, que las existentes no satisfacen».

Como subraya DUQUE, «el grupo cooperativo del artículo 78 LC ha roto con la relación casi necesaria con la cooperativa de segundo grado, que, con anterioridad a la LC 1999, se utilizaba habitualmente como instrumento del grupo cooperativo» ${ }^{45} \mathrm{y}$ «tiene la finalidad de re-

${ }^{44}$ En el mismo sentido, véase SANZ JARQUE, J. J., Actualización de la Ley General de Cooperativas de España (Ley 3/1987, de 2 de abril), en Boletín Asociación Internacional de Derecho Cooperativo, Núm. 32/1999-I, Universidad de Deusto, Bilbao, 1999, pág. 17.

45 DUQUE, J. y RUIZ PERIS, J. I., op. cit., pág. 112. 
forzar en el mercado cada vez más competitivo a la sociedad cooperativa como forma de explotar una empresa económica» ${ }^{46}$.

Se define como grupo cooperativo, a los efectos de la LCE, el conjunto formado por varias sociedades cooperativas (con independencia de su clase) y la entidad cabeza de grupo, que ejercita facultades o emite instrucciones de obligado cumplimiento para las cooperativas agrupadas, de forma que se produce una unidad de decisión en el ámbito de dichas facultades.

Apuntaba acertadamente RUIZ PERIS, en relación a la idéntica estatal, que «el artículo 78 hace referencia a la cabeza del grupo con el término "entidad" en el que pueden quedar incluidas tanto todas las de economía social, y no sólo las cooperativas, como las sociedades mercantiles o incluso civiles, como es actualmente el caso del Grupo Mondragón» ${ }^{47} 48$.

El Grupo debe, evidentemente, ajustar su funcionamiento a los principios cooperativos en los términos previstos en el artículo 1.2 de la LCE, que lo declara así de forma expresa ${ }^{49}$.

\section{3. Ámbitos grupales}

Las instrucciones de obligado cumplimiento pueden afectar a distintos ámbitos de gestión, administración o gobierno, señalando la LCE, expresamente, que pueden incluirse los siguientes:

- El establecimiento en las cooperativas de base de normas estatutarias y reglamentarias comunes.

- El establecimiento de relaciones asociativas entre las entidades de base.

- Los compromisos de aportaciones periódicas de recursos calculados en función de su respectiva evolución empresarial o cuenta de resultados.

La relación es enunciativa, «la LGC establece un catálogo enunciativo de los ámbitos en los que podrá concederse facultades a la socie-

46 Ibid, pág. 104.

47 DUQUE, J. y RUIZ PERIS, J. I., op. cit, pág. 159. Desarrolla los supuestos en que una fundación o una cooperativa sean cabeza de grupo, en sus páginas 138 a 166.

48 En similar sentido: EMBID IRUJO, J. M., Problemas..., op. cit., págs.24 y 25 y VICENT CHULIA, F., op. cit., pág. 534.

49 Esta declaración expresa no se contiene en el texto de la LC estatal. 
dad cooperativa cabeza de grupo para que imparta instrucciones de obligado cumplimiento a las cooperativas pertenecientes al mismo» 50 .

Para EMBID IRUJO51, con el artículo se «avanza decididamente en el reconocimiento del poder de dirección en los grupos integrados (exclusivamente o no) por cooperativas, imponiendo el carácter vinculante de las instrucciones que se impartan por la dirección del grupo».

No obstante, la LCE matiza que el carácter obligatorio de las instrucciones emitidas o de las facultades a ejercer debe tener soporte en los compromisos generales asumidos ante el Grupo.

Se prevé, adicionalmente, que no pueden exigirse dichos compromisos generales en caso de que una o varias cooperativas del mismo hayan sido expresamente exoneradas de las mismas. Realmente, lo que se recalca no es tanto que no puede exigirse algo a quien se exoneró, lo cual es evidente, como que cabe exonerar a cooperativas del grupo de compromisos generales, con lo que se posibilita una mayor integración o asunción de nuevos compromisos entre las cooperativas que así lo quieran, dejando fuera de ellos a las que no desean participar ${ }^{52}$.

\subsection{Incorporaciones}

La aprobación de la incorporación al Grupo cooperativo precisa del acuerdo inicial de cada una de las entidades de base, alcanzado conforme a sus propias reglas de competencia y funcionamiento.

Como indica DUQUE53, «el contenido del acuerdo no puede limitarse a emitir una declaración favorable a la participación en el grupo cooperativo. La propuesta elaborada por el Consejo Rector ${ }^{54}$ debe incluir los datos individualizadores del grupo cooperativo del que pretende formar parte la cooperativa que convoca la Asamblea. Pero es indudable que los socios convocados deberán tener conocimiento del contenido del acuerdo en el momento de la votación».

50 DUQUE, J. y RUIZ PERIS, J. I., op. cit, pág. 160.

51 EMBID IRUJO, J. M., Problemas..., op. cit., pág. 28.

52 Estos dos párrafos comentados sólo aparecen en la LCE y no en la LC.

53 DUQUE, J. y RUIZ PERIS, J. I., op. cit, pág. 123.

54 Para el mismo autor, es «razonable atribuir al Consejo Rector la competencia de comenzar los tratos para configurar el grupo, pero siempre que, una vez creado, la Asamblea General tenga la competencia de discutirlo y, en su caso, de aprobarlo» (Ibid., pág. 122). 


\subsection{Formalización y modificación de los compromisos}

La LCE exige que los compromisos generales asumidos se formalicen:

- Si la entidad cabeza de grupo es cooperativa: en sus propios Estatutos Sociales.

— Si no lo es: en escritura pública exigiéndose que en tal caso se incluya:

- La duración del mismo, si ésta es limitada.

- El procedimiento para la modificación de dichos compromisos.

- El procedimiento para la separación de una cooperativa miembro.

- Las facultades cuyo ejercicio se atribuyan a la entidad cabeza de grupo.

Este contenido mínimo exigido cuando la cabecera no sea cooperativa, trata de garantizar una regulación mínima, dado que cuando la cabecera es cooperativa sus estatutos deben respetar el contenido mínimo que la LCE establece.

Por último, la LCE prevé que se pueda establecer que los compromisos generales ${ }^{55}$ puedan modificarse, ampliarse o resolverse mediante acuerdo del órgano máximo cabeza de grupo.

\subsection{Clases}

El Reglamento de la Ley de Cooperativas de Euskadi establece que, en función del grado de integración económica, los grupos cooperativos se clasifican en dos clases: grupos cooperativos por integración y grupos cooperativos por colaboración, indicando que se entienden como tales a efectos del Reglamento:

a) Grupos cooperativos por integración. Se definen como aquellos que cumplen a la vez todos los siguientes requisitos:

- Dirección única del grupo cooperativo en su conjunto.

- Nivel de centralización efectiva de las facultades de gestión económica que permita entender que, pese al mantenimiento de entidades jurídicamente diferenciadas, existe una verdadera unidad económica.

55 Para RUIZ PERIS, los «compromisos» pueden ser identificados con las «facultades» que se atribuyen a la sociedad cooperativa cabeza de grupo (Ibid., pág. 160). 
El Reglamento establece una presunción de unidad económica cuando, junto a la dirección general común, se cumple alguno de los siguientes extremos:

- Existencia de relaciones de hecho comerciales, financieras o patrimoniales que supongan una dependencia efectiva de alguna de las entidades de grupo.

- Existencia de un acuerdo de responsabilidad solidaria frente al exterior por operaciones que realicen directamente con terceros las sociedades cooperativas integradas en el grupo, siempre que tengan carácter de permanencia y que se trate de operaciones necesarias y no auxiliares para la realización de su actividad empresarial.

- Existencia de compromiso de aportación periódica de recursos, calculados en función de la cuenta de resultados de la respectiva cooperativa, cuya cuantía a aportar supere el cincuenta por ciento de los excedentes netos previos de cada cooperativa.

- Existencia, entre dos o más sociedades del grupo cooperativo, de relaciones que cumplan los requisitos que generan la obligación de consolidar cuentas tal y como se regula en los artículos 42.1 y 43 del Código de Comercio.

Adicionalmente, se indica que, cuando cualquiera de los cuatro supuestos anteriores se produzca únicamente con respecto de algunas de las cooperativas integradas en el grupo, son exclusivamente éstas las que se consideran como parte de un grupo cooperativo de integración.

- Grupos cooperativos por colaboración. Se establece una definición por exclusión, indicando que lo son los que no sean grupos cooperativos por integración.

\subsection{Efectividad del régimen de Grupos cooperativos}

El régimen de grupos cooperativos previsto en el artículo 135 bis de la LCE, es efectivo, según su Reglamento, desde el momento en que se cumplan los requisitos previstos en dicho artículo.

\subsection{Control registral}

La LCE establece una prevención más propia del Reglamento del Registro de Cooperativas, cual es la obligación de que se anote en la 
hoja que cada sociedad cooperativa miembro tiene en el Registro de Cooperativas la pertenencia a un grupo y, en su caso, la separación del mismo.

La anotación, tanto de pertenencia como de separación a un grupo cooperativo, se realiza a petición de la cooperativa interesada, sin que la ausencia de inscripción afecte a la plena vigencia y efectividad de las previsiones del artículo 135 bis.

Estas normas legales se encuentran igualmente en el propio RRCE (artículo 50), que adiciona la obligación de la entidad cabeza de Grupo que sea sociedad cooperativa de inscribirse y promover la inscripción de todos los actos de dicha entidad y de los acuerdos de integración y separación de sus integrantes.

A ello debemos añadir la obligación general de las cooperativas de realizar la inscripción del nombramiento y cese de administradores, miembros de la Comisión Ejecutiva, Consejeros Delegados, Directores Gerentes y miembros de la Comisión de Vigilancia de los Grupos Cooperativos (artículo 11.4 RRCE).

Por último, se prevé que los grupos cooperativos, que conforme a la normativa contable estén obligados a consolidar las cuentas y lo hagan efectivamente, deben presentarlas en el Registro de Cooperativas

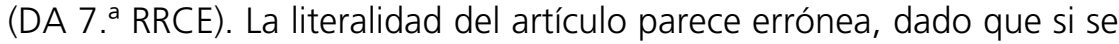
declara la obligación, ésta debe cumplirse. Parece más lógico pensar que falta en el artículo un «y los que», de forma que puedan depositar los que sin estar obligados realicen dicha consolidación.

\subsection{Responsabilidad entre miembros del Grupo y entre éstos y la cabecera}

La LCE establece de forma expresa que la responsabilidad que se derive de operaciones que realicen las sociedades cooperativas integradas en un grupo directamente con terceros, no alcanzan al grupo, ni a las demás sociedades cooperativas que lo integran ${ }^{56}$.

Debe subrayarse que sólo se aclara la exclusión con esas condiciones, debiéndose analizar los posibles supuestos de responsabilidad caso por caso.

56 Sobre esta cuestión, puede verse por todos: DUQUE, J. y RUIZ PERIS, J. I., op. cit, págs. 130 y 131 y URIA, R., op. cit., págs. 638 a 640. Sobre la responsabilidad de los administradores de los grupos: SANCHEZ ALVAREZ, M. M., Grupos de sociedades y responsabilidad de los administradores, RDM, Núm. 227, Madrid, 1998, págs. 117 y ss. 


\section{Cooperativas mixtas (artículo 136 LCE y DA $2 .{ }^{a}$ RRCE)}

\subsection{Definición y objeto}

Se entiende como Cooperativa Mixta de la LCE a aquella en la que existen socios minoritarios cuyo derecho de voto en la Asamblea General está determinado, de modo exclusivo o preferente, en función del capital aportado. Este puede estar representado por medio de títulos o anotaciones en cuenta, sometidos a la legislación reguladora del mercado de valores.

Señala la Exposición de Motivos que es «una de las innovaciones más radicales de la Ley», y que en ellas "a modo de comanditarias cooperativas, habrá dos bloques de socios cuyos respectivos derechos tanto políticos como económicos, tendrán distinto origen y alcance, pero sin que pueda orillarse un efectivo predominio en la sociedad del componente estrictamente cooperativo».

Las razones de «esta novedosa regulación, solicitada desde algunos sectores del cooperativismo de Euskadi» es "ofrecer un nuevo cauce de organización empresarial ligado al método cooperativo pero atento también a los nuevos desafíos y exigencias de unos mercados cada vez más agresivos y competitivos, tanto para captar recursos como a la hora de producir y distribuir bienes y servicios» (E. de M.).

\subsection{Derecho de voto en la Asamblea General}

La LCE establece unos límites de distribución del derecho de voto en estas cooperativas:

- Al menos el cincuenta y uno por ciento de los votos debe atribuirse, en la proporción que se defina en los Estatutos, a socios cooperadores.

- Una cuota máxima, que debe determinarse en Estatutos, del cuarenta y nueve por ciento de los votos, se distribuye en partes sociales con voto. Estas partes pueden ser libremente negociables en el mercado si los Estatutos los prevén ${ }^{57}$.

57 El RRCE reitera la exigencia de que se regulen en los Estatutos Sociales de las cooperativas mixtas estas cuotas (DA 2. ${ }^{a}$ ). 


\subsection{Régimen legal aplicable a las partes sociales con voto}

Los derechos y obligaciones de los titulares de las partes sociales con voto, así como el régimen de las aportaciones, deben ser regulados en los Estatutos Sociales ${ }^{58}$. Supletoriamente, se aplica lo dispuesto en la legislación de sociedades anónimas para las acciones.

\subsection{Participación en excedentes}

La participación de cada uno de los grupos de socios en los excedentes anuales a distribuir, sean positivos o negativos, se determina en proporción al porcentaje de votos que cada uno de los dos colectivos ostente.

Dentro del grupo de socios poseedores de partes sociales con voto, los excedentes se distribuyen entre ellos en proporción al capital desembolsado.

En cuanto a los restantes socios, los excedentes se distribuyen según los criterios generales que la LCE establece para las cooperativas ordinarias.

\subsection{Modificaciones de derechos u obligaciones de alguno de los dos colectivos}

A fin de proteger el equilibrio pactado entre los dos colectivos de socios, la LCE exige que cualquier modificación autorreguladora que afecte a derechos y obligaciones de algunos de los dos colectivos de socios, tenga el consentimiento mayoritario del grupo correspondiente. Este puede obtenerse en una votación separada en la Asamblea General o en una Junta especial y parcial.

Sin ese acuerdo, la modificación no es válida.

\subsection{Regla especial de liquidación}

La LCE posibilita la repartibilidad del Fondo de Reserva Obligatorio en caso de liquidación. Para ello, es preciso que en el momento de la

58 El RRCE reitera la obligación de la regulación en los Estatutos Sociales de las cooperativas mixtas de esta materia (DA 2. ${ }^{a}$ ). 
configuración, constitutiva o por modificación, de estas Cooperativas, el Consejo Superior de Cooperativas de Euskadi autorice una previsión en Estatutos en tal sentido.

En tal caso, el reparto se debe realizar conforme a los criterios de participación en excedentes, respetándose las demás normas de adjudicación del haber social establecidas en la LCE. 